\title{
Profile of intestinal stomas at a tertiary referral centre of central India
}

\author{
Rajkumar ${ }^{1}$, Singh $\mathrm{M}^{2}$, Neogi $\mathrm{P}^{3}$, Ajay $\mathrm{SK}^{4},{\text { Gupta } \mathrm{V}^{5}}^{5}$ \\ ${ }^{1}$ Dr Rajkumar, Assistant Professor, ${ }^{2}$ Dr Mayank Singh, Assistant Professor ${ }^{3}$ Dr Probal Neogi, Professor, \\ ${ }^{4}$ Dr Sunil Kumar, Junior Resident, ${ }^{5}$ Dr Vivek Gupta, Junior Resident PG department of Surgery. All are affiliated with \\ MLN Medical College, Allahabad, UP, India.
}

Address for correspondence: Dr Vivek Gupta, Email: vivekrocksalld@ gmail.com

\begin{abstract}
Aim: The aim of study was to evaluate various types of stoma with regard to their indications, their complications and methods to reduce them, at a tertiary hospital of central India. Methods: The study was carried out in Department of surgery at M. L. N. Medical College, Allahabad from August 2013 to July 2014. Adult patients who were admitted here and had Ileostomy/colostomy formation/closure as a part of their treatment were included. Data was collected by meticulous history taking, clinical examination and investigations. Results: A total of 100 patients were included (Avg. 34 year) and male: female ratio was 1.6:1. The most common stoma constructed was ileostomy (82\%) with loop ileostomy (62\%) being the most common subtype. Among colostomies, loop was most common (50\%). Main indication of stoma formation was intestinal perforation (63\%). In individual causes, Typhoid Perforation (44\%) was most common indication. $85 \%$ patients had stoma complications, most common being peristomal skin excoriation (80\%). Study of closure of stoma was done in a total of 50 patients. Closure of 43 ileostomies and 7 colostomies was done. Mean length of postoperative stay was 11 days. $28 \%$ developed complication among which paralytic ileus, (16\%) was most common. Conclusion: Despite extensive surgical experience, complications of intestinal stomas still occur frequently and result in high morbidity. Meticulous skin care with regular follow-up, early detection of complications with their timely management along with education and counseling can decrease morbidity.
\end{abstract}

Key-words: Intestinal stoma, Indications, Complications, Stoma closure.

\section{Introduction}

The word "stoma" is originated from Greek word which means mouth or opening [1]. A stoma is an artificial communication between organs or viscera and the external environment, for feeding, drainage and elimination [2]. The most common abdominal stomas are the ileostomy and colostomy [3].

The creation of intestinal stomas is an integral component of the surgical management of several disease processes involving the gastrointestinal tract. Despite extensive surgical experience, complications of intestinal stomas still occur [4].

There are many indications for which stomas (both ileostomy and colostomy) are constructed. Colostomy is constructed often for distal obstructing lesion causing

Manuscript received 24 ${ }^{\text {th }}$ April 2016

Reviewed: $5^{\text {th }}$ May 2016

Author Corrected: $15^{\text {th }}$ May 2016

Accepted for Publication 29 May 2016 massive dilation of proximal colon. Diverting ileostomy provides for diversion of intestinal content as a part of abdomino-perineal resection [5].

Information about the types and number of stomas constructed, complications of the stoma, and resultant impairments of an individual's life has been limited in Indian set-up. The aim of our study is to evaluate various types of stoma and their indications, their complications, involved factors and ways to reduce complications, at a tertiary centre of central India.

\section{Material and Methods}

The study was carried out in P.G. Department of surgery, S.R.N. Hospital associated with M.L.N. Medical College, Allahabad from August 2013 to July 2014 after approval from the ethical committee and obtaining written and informed consent from the patients. All adult patients who were admitted during 
that period, on emergency or OPD basis, whose stoma were either constructed or closed here or who were admitted for any complication of stoma, constructed here or elsewhere, were included in this study. Age, gender, other variables regarding the history of pain, fever, treatment before hospitalization, probable date of perforation/ obstruction, clinical variables like anaemia, hydration, jaundice, temperature, blood pressure, pulse and respiration rate, operative findings including indication for stoma formation, peritoneal contamination and details of surgical procedure were recorded. Various complications occurring due to stoma during postoperative period or follow up were recorded. As no formal enterostomal therapist was available in our set up, the preoperative counselling and psychological preparation of the patients for stoma was done by the operating surgeon.

The results were collected, analysed and compared with other studies. Patients younger than 18 years, urinary conduits, and psychological and biochemical complications of stoma were excluded from the study.

\section{Results}

Stoma formation: A total of 100 patients were included in the study. The maximum number of patients were in the age group of 18-30yrs. $(n=55)$. Average age in study group is 34 years (ranges 18-70). 62 patients were male and 38 were female. The average age for women was 32 years, ranging from 18 to 65 years, and that of men 35 years, ranging from 18 to 70 years. 94 Patients presented with acute Abdomen and were operated in emergency OT for exploratory laparotomy while 6 were operated in elective OT. In 9\% cases stoma formation was done during re-exploration surgery due to anastomosis leak in primary surgery or after stoma closure. Pre op stoma site marking was done in 5\% selected cases of Solitary Rectal Ulcer Syndrome, recto-vesical fistula, which were operated in Elective OT.

39 out of 100 patients had previous comorbid conditions like Hypertension/ Diabetes/ Tuberculosis. Most of the patients admitted in emergency (94\% of the total) were febrile $(65 \%)$ and had pedal edema (54\%), clubbing (15\%) or lymphadenopathy $(5 \%)$. Most of the patients had pallor $(68 \%)$. Low blood protein $(<4 \mathrm{gm} / \mathrm{dl})$ and low albumin level $(<3.5 \mathrm{gm} / \mathrm{dl})$ was present in $47 \%$ and $51 \%$ patients respectively.

The most common stoma constructed was ileostomy (82 out of 100), with loop ileostomy being the most common subtype of ileostomy performed (62 out of 82 ileostomies). End ileostomy was done in 8 patients and double barrel ileostomy in 12 patients. Colostomy was done in 18 patients, out of which 9 were loop colostomies, 8 end colostomies and 1 double barrel colostomy. Most common stoma constructed was ileostomy-loop/end/double barrel (82\%). The most common stoma site was right lower abdomen ( $84 \%)$, followed by left iliac fossa (13\%), right upper quadrant (2\%) and left upper quadrant $1 \%$.

Most common indication of stoma formation was intestinal perforation (63\%) while intestinal obstruction (31\%) was second most common indication. In individual causes, typhoid perforation (44\%) was the most common indication, followed by tubercular perforation (11\%) penetrating injury (4\%) and carcinoma (6\%).

Stoma complications: Eighty-five patients $(85 \%)$ had stoma complications, which included peristomal skin excoriation $(80 \%)$, diarrhoea $(30 \%)$, mucosal prolapse and retraction $(27 \%$ each).

Other local complications included improper stoma site creation with poor fitting appliance (17\%), prolapse (14\%), stenosis/stricture (7\%) were equally common in ileostomy or colostomy. Faecal fistula (4.8\% vs 5\%) was equally common in ileostomy or colostomy. Vascular compromise $(8.5 \%$ vs $11.1 \%)$ was more common in colostomy. Septicemia $(38.8 \%)$ was more common in colostomy. Electrolyte imbalance (30.5\% vs $22.2 \%)$ was more common in ileostomy.

Complications were seen more in loop ileostomy as compared to other stoma types. Most common complications of loop ileostomy were peristomal skin excoriation (95.1\%), diarrhea (38.7\%), gaping of the main wound (46.7\%). End colostomy seemed to have more complication than loop colostomy.

Retraction (50\%) was more common in double barrel ileostomy and end colostomy as compared to loop ileo/colostomy. Prolapse $(33.3 \%)$ and parastomal hernia $(25 \%)$ were more common in double barrel ileostomy as compared to loop ileostomy. Parastomal hernia $(6 \%)$ and stomal bleeding/ peristomal varices $(6 \%)$ were only seen in ileostomy. 
$56 \%$ of the patients suffered from systemic complications which included gaping of main wound (37\%). Electrolyte imbalance $(28 \%)$ was more in ileostomy. Septicemia (25\%) and fecal fistula (5\%) was equally common in ileostomy and colostomy.

Due to low literacy rate and poverty, $45 \%$ patients were unable to understand the care of stoma and uses of stoma appliance and accessories. Most stomates (90\%) used cheap stoma kit which is unable to prevent leakage of enteric contents and thus potentiated skin irritation.

Table- 1: Indication of stoma formation.

\begin{tabular}{|l|l|l|}
\hline Indication & Frequency & \%GE \\
\hline Intestinal perforation & 63 & $63 \%$ \\
\hline Typhoid & 44 & $44 \%$ \\
\hline Tubercular & 11 & $11 \%$ \\
\hline Penetrating(Stab/Firearm) & 4 & $4 \%$ \\
\hline Iatrogenic & 2 & $2 \%$ \\
\hline Blunt trauma abdomen & 2 & $2 \%$ \\
\hline Intestinal Obstruction & 31 & $31 \%$ \\
\hline Carcinoma & 6 & $6 \%$ \\
\hline Intussuception & 5 & $5 \%$ \\
\hline Volvulus & 5 & $5 \%$ \\
\hline Gangrenous bowel & 4 & $4 \%$ \\
\hline Tuberculosis & 4 & $4 \%$ \\
\hline Postoperative adhesion & 4 & $4 \%$ \\
\hline Colitis & 2 & $2 \%$ \\
\hline Strangulated hernia & 1 & $1 \%$ \\
\hline Rectovaginal/vesical fistula & 2 & $2 \%$ \\
\hline Solitary Rectal Ulcer Syndrome & 1 & $1 \%$ \\
\hline Exact cause not known & 3 & $3 \%$ \\
\hline
\end{tabular}

Table-2: Different complications of stoma.

\begin{tabular}{|l|l|l|}
\hline Local complications & Number & \%age \\
\hline Peristomal skin irritation- Excoriation, Dermatitis, Desquamation & 80 & $80 \%$ \\
\hline Improper Stoma creation site & 17 & $17 \%$ \\
\hline Vascular compromise & 9 & $9 \%$ \\
\hline Mucosal prolapse & 27 & $27 \%$ \\
\hline Stenosis, Stricture, Blocked & 7 & $7 \%$ \\
\hline Diarrhoea due to irritation & 30 & $30 \%$ \\
\hline Prolapse & 14 & $14 \%$ \\
\hline Retraction & 27 & $27 \%$ \\
\hline Parastomal Hernia & 6 & $6 \%$ \\
\hline Stomal Bleeding/ Peristomal varices & 6 & $6 \%$ \\
\hline Systemic complications & & \\
\hline Electrolyte imbalance & 28 & $28 \%$ \\
\hline Septicemia & 25 & $25 \%$ \\
\hline Gaping of main Wound & 37 & $37 \%$ \\
\hline Faecal fistula & 5 & $5 \%$ \\
\hline
\end{tabular}


Table-3: Different complications of stoma in Ileostomy \& colostomy.

\begin{tabular}{|l|l|l|}
\hline Complications & Ileostomy (n=82) & Colostomy(n=18) \\
\hline $\begin{array}{l}\text { Peristomal skin irritation- Excoriation, Dermatitis, } \\
\text { Desquamation }\end{array}$ & $67(81.7 \%)$ & $13(72.2 \%)$ \\
\hline Improper Stoma creation site & $14(17 \%)$ & $3(16.6 \%)$ \\
\hline Vascular compromise & $7(8.5 \%)$ & $2(11.1 \%)$ \\
\hline Mucosal prolapse & $25(30.5 \%)$ & $2(11.1 \%)$ \\
\hline Stenosis, Stricture, Blocked & $6(7.3 \%)$ & $1(5.5 \%)$ \\
\hline Diarrhoea due to irritation & $29(35.4 \%)$ & $1(5.5 \%)$ \\
\hline Prolapse & $12(14.6 \%)$ & $2(11.1 \%)$ \\
\hline Retraction & $20(24.4 \%)$ & $6(7.3 \%)$ \\
\hline Parastomal Hernia & $6(7.3 \%)$ & 0 \\
\hline Stomal Bleeding/ Peristomal varices & $6(7.3 \%)$ & 0 \\
\hline Electrolyte imbalance & $25(30.5 \%)$ & $4(22.2 \%)$ \\
\hline Septicemia & $19(23.2 \%)$ & $7(38.8 \%)$ \\
\hline Gaping of main Wound & $33(40.2 \%)$ & $3(16.6 \%)$ \\
\hline Faecal fistula & $4(4.8 \%)$ & $1(5.5 \%)$ \\
\hline
\end{tabular}

Table-4: Specific complication in each type of stoma.

\begin{tabular}{|c|c|c|c|c|c|c|}
\hline Complications & $\begin{array}{l}\text { Loop } \\
\text { ileostomy } \\
(n=62)\end{array}$ & $\begin{array}{l}\text { End } \\
\text { ileostomy } \\
(n=8)\end{array}$ & $\begin{array}{l}\text { Double } \\
\text { barrel } \\
\text { ileostomy } \\
(n=12) \\
\end{array}$ & $\begin{array}{l}\text { Loop } \\
\text { colostomy } \\
(n=9)\end{array}$ & $\begin{array}{l}\text { End } \\
\text { colostomy } \\
(n=8)\end{array}$ & $\begin{array}{l}\text { Double } \\
\text { barrel } \\
\text { colostomy } \\
(n=1)\end{array}$ \\
\hline $\begin{array}{l}\text { Peristomal skin } \\
\text { irritation }\end{array}$ & $59(95.1 \%)$ & $6(75 \%)$ & $2(16.67 \%)$ & $6(66.6 \%)$ & $7(87.5 \%)$ & 0 \\
\hline Improper Stoma site & $10(16.1 \%)$ & 0 & $4(33.33 \%)$ & $1(11.1 \%)$ & $2(25 \%)$ & 0 \\
\hline $\begin{array}{l}\text { Vascular } \\
\text { compromise }\end{array}$ & $5(8.06 \%)$ & $1(12.5 \%)$ & $1(8.3 \%)$ & 0 & $2(25 \%)$ & 0 \\
\hline Mucosal prolapse & $19(30.6 \%)$ & $2(25 \%)$ & $4(33.33 \%)$ & $1(11.1 \%)$ & $1(12.5 \%)$ & 0 \\
\hline $\begin{array}{l}\text { Stenosis/Stricture/B } \\
\text { lockage }\end{array}$ & $4(6.45 \%)$ & 0 & $2(16.67 \%)$ & 0 & 0 & 1 \\
\hline $\begin{array}{l}\text { Diarrhoea due to } \\
\text { irritation }\end{array}$ & $24(38.7 \%)$ & $1(12.5 \%)$ & $4(33.33 \%)$ & 0 & $1(12.5 \%)$ & 0 \\
\hline Prolapse & $8(12.9 \%)$ & 0 & $4(33.33 \%)$ & $2(22.2 \%)$ & 0 & 0 \\
\hline Retraction & $12(19.3 \%)$ & $2(25 \%)$ & $6(50 \%)$ & $2(22.2 \%)$ & $4(50 \%)$ & 1 \\
\hline Parastomal Hernia & $3(4.8 \%)$ & 0 & $3(25 \%)$ & 0 & 0 & 0 \\
\hline $\begin{array}{l}\text { Stomal Bleeding/ } \\
\text { Peristomal varices }\end{array}$ & $5(8.06 \%)$ & 0 & $1(8.3 \%)$ & 0 & 0 & 0 \\
\hline $\begin{array}{l}\text { Electrolyte } \\
\text { imbalance }\end{array}$ & $15(24.2 \%)$ & $3(37.5 \%)$ & $7(58.3 \%)$ & $3(33.3 \%)$ & $1(12.5 \%)$ & 0 \\
\hline Septicemia & $9(14.5 \%)$ & $2(25 \%)$ & $8(66.7 \%)$ & $3(33.3 \%)$ & $4(50 \%)$ & 0 \\
\hline $\begin{array}{l}\text { Gaping of main } \\
\text { Wound }\end{array}$ & $29(46.7 \%)$ & $3(37.5 \%)$ & $2(16.67 \%)$ & $2(22.2 \%)$ & $1(12.5 \%)$ & 0 \\
\hline Faecal fistula & $3(4.8 \%)$ & $1(12.5 \%)$ & 0 & $1(11.1 \%)$ & 0 & 0 \\
\hline Death & $7(11.2 \%)$ & $1(12.5 \%)$ & $6(50 \%)$ & $1(11.1 \%)$ & $1(12.5 \%)$ & 0 \\
\hline
\end{tabular}


Table- 5: Types of stoma that were closed.

\begin{tabular}{|l|l|l|}
\hline Procedures & Numbers & \%AGES\% \\
\hline Ileostomy & $\mathbf{4 3}$ & $\mathbf{8 6 \%}$ \\
\hline Loop ileostomy & 34 & \\
\hline End ileostomy & 4 & \\
\hline Double barrel ileostomy & 5 & \\
\hline Colostomy & 7 & $\mathbf{1 4 \%}$ \\
\hline Loop colostomy & 4 & \\
\hline End colostomy & 3 & \\
\hline
\end{tabular}

Stoma Closure: A total of 50 patients were included in the study. The maximum number of patients were in the age group of 18-30yrs. $(n=29)$. Average age in study group is 34 years (range 18-70). 29 were male and 21 were female patients. The average age for women was 33 years, (range 18 to 55 years) and that of men 32 years (range 18 to 70 years). The average time after which stoma closure was done was 18 weeks (range 9- 36 weeks).

Stoma closure of 43 cases of ileostomy and 7 cases of colostomy (total 50 patients) was done in the study period. There were 34 cases of loop ileostomy, 5 cases of double barrel and 4 cases of end ileostomy. 4 cases of loop colostomy and 3 cases of end colostomy were closed.

Most cases for stoma closure were operated previously for intestinal perforation (74\%) or obstruction (20\%). Before closure of stomas, all patients underwent loopogram/ gastrograffin enema to confirm the integrity of distal segment. The mean length of postoperative stay was 11 days (ranges 6-28 days). Fourteen (28\%) of the 50 patients developed at least one complication and $6 \%$ developed multiple complications. The most common complications were paralytic ileus (16\%) and obstruction (6\%) both of which responded to conservative management. Anastomotic leak occurred in $6 \%$ of patients for which re-exploration was done. In all such cases ileostomy reformation was done.

\section{Discussion}

Ileostomy/colostomy: In our study done on 100 patients, 82 ileostomies and 18 colostomies were performed, while in a similar study by Hellman $\mathbf{J}$ et al [6] reported 93 patients with 58 ileostomy and 35 colostomy formation. In our study mean age was 34 years (range 18 to 70 year), while in a similar study by Nastro P et al [7] mean age was 64 years and in Cheape JD et al [8] mean age was 36 years (range 11 to 68 ).

In our study, among 82 ileostomies, loop ileostomy (75\%) was most common type of ileostomy. End ileostomy was performed in $9.7 \%$ and double barrel ileostomy in $14.6 \%$ patients. In similar study by Cheape JD et al [8] 36 loop ileostomies were performed.

In our study, colostomy was done in 18 patients, $50 \%$ were loop colostomies, $44.4 \%$ were end colostomies and $5.5 \%$ were double barrel colostomy, while similar study by Hwang YF et al [9] reported $49.7 \%$ end colostomy, $37.8 \%$ loop colostomy and $15 \%$ double barrel colostomy.

The most common indication of stoma formation in our study was enteric fever perforation in $38 \%$ cases followed by tubercular perforation in $11 \%$ cases and carcinoma rectum in $6 \%$ cases. Study of Akram Rajput et al [10] reported enteric perforation $(60 \%)$ as the commonest indication of stoma formation. Adnan Aziz et al [11] demonstrated typhoid perforation (66\%) followed by tuberculosis as the most common indication. In contrast, a study of Safirullah et al [12] showed colorectal carcinoma $(22 \%)$ as the most common indication followed by trauma (20\%) and typhoid perforation $(20 \%)$.

In our study overall complication rate was $80 \%$, while other similar studies showed a complication rate which is significantly less than our study [13-20]. Complication rate is high in our study compared to other studies because most patients presented with acute abdomen and were operated in emergency OT for exploratory laparotomy, pre-op stoma site marking was not done in most patients $(95 \%)$ and no enterostomal therapy nurse was available in our hospital.

In our study, $85 \%$ of the total complications were local stoma related. $56 \%$ of the total complications were systemic in nature. In a study by Kalashinikova I et al [20] stoma-related and peristomal skin complications 
were $69.9 \%$ and $64.2 \%$, respectively, while Formijne Jonkers HA et al [21] reported that $82 \%$ of the patients had stoma-related complications.

In our study most common local stomal complication was peristomal skin irritation- excoriation, dermatitis, desquamation $(80 \%)$. In other studies peristomal skin complications occurred in $7.3 \%$ to $89 \%$ of patients $[13,15,16,20,21,23]$.

In our study other local stoma complications were diarrhoea due to irritation (30\%), mucosal prolapse $(27 \%)$, retraction $(27 \%)$, parastomal hernia $(6 \%)$, stomal bleeding/peristomal varices (6\%), improper stoma site creation (17\%), prolapse (14\%), stenosis/stricture (7\%), vascular compromise/stomal necrosis $(9 \%)$, while in a similar study by Duchesne et al [15] reported complications were stomal necrosis (4.3\% of all patients, $17.1 \%$ of complications), and stoma retraction $(1.2 \%$ of all patients, $4.6 \%$ of complications). Arumagam et al [17] reported complications were retraction (23 patients), poor stoma site (18 patients) in 97 stomas. Redmond C et al [22] reported $20 \%$ complications of bothersome folds and scars and $17 \%$ parastomal hernias, stomal retraction $(10 \%)$ and prolapse $(1 \%)$. Nastro $\mathrm{P}$ et al [7] reported $46.4 \%$ complications, of which the commonest was parastomal hernia $14 \cdot 1 \%$.

A study by Kalashinikova I et al [20] reported stoma complications including parastomal hernia (25.1\%), mucocutaneous separation (18.6\%), prolapse (16.8\%), retraction $(14.2 \%)$, stenosis $(7.8 \%)$, mucosal hypergranulation $(7.8 \%)$, and fistula $(4.9 \%)$. In a study by Formijne Jonkers HA et al [21] reported complications were fixation problems (46\%) and leakage (40\%). Superficial necrosis, bleeding and retraction occurred in $20 \%, 14 \%$ and $9 \%$ of patients, respectively.

In our study complications were seen more in loop ileostomy as compared to other stoma types. More common complication of loop ileostomy was peristomal skin excoriation (95.1\%). Park et al [13] reported highest incidence of complications in loop ileostomy (75\%) and lowest in end transverse colostomy (6\%).

In our study pre op stoma site marking was done in selected $(5 \%)$ cases which were operated in elective OT. Improper stoma site was found in $17 \%$ patients. While in study of Park et al [13] 26\% of patients underwent preoperative marking by an ET nurse. It demonstrated significant decrease in incidence of stoma complications. Bass et al [23] also emphasizes the need for preoperative stoma marking.

In our study parastomal hernia was seen in $6 \%$ of the patients in which stoma formation was done- majority of the parastomal hernias $(25 \%)$ were seen in Doublebarrel ileostomy. Other studies reported rate of parastomal hernia as Park et al [13] (1.18\%) and Porter JA et al [24] (9.3\%).

Stoma Closure: During this study 50 stomas were closed, 29 were male (avg. age $32 \mathrm{yrs}$ ) and 21 were female patients (avg. age 33 yrs). Among closures, 43 ileostomy closures were performed with complication rate of $28 \%$. A study by Bakx et al [25] reported $42 \%$ complication rate, while in study of Pavoordt HD et al [26] the overall complication rate was $17 \%$.

In our study the average time after which stoma closure was done was 18 weeks (ranges 9- 36 weeks). The mean length of postoperative stay after stoma closure was 11 days (ranges 6-28 days), while a study by Parks SE et al [27] reported that patients who underwent closure after 90 days interval had a lower overall complication rate.

A study by Pittman DM et al [28] reported average hospitalization was 11.1 days for patients without complications, 15.5 days for those with wound infection, 18.5 days for patients with ileus, and 20.4 days for patients with anastomotic leaks. A study by Khoury DA et al [29] reported that stomas were closed after 116 days and overall hospital stay for closure was 11.5 days.

In our study 7 cases of colostomy closure was done with a complication rate of $35 \%$. Similar studies by Mirelman D et al [30] reported morbidity rate of $49.1 \%$, Bozzetti $F$ et al [31] reported complication rate of 24.6\%, Parks SE et al [23] reported a complication rate of $36 \%$ and Pittman DM et al. reported complication rate was $33 \%$ [24].

In our study most common complications were paralytic ileus (16\%), obstruction (6\%) and anastomotic leak in $6 \%$, while a study by Bozzetti $\mathrm{F}$ et al [31] reported overall complication rate was 24.6 per cent, including infections (13.8 per cent), fistulas (6.1 per cent), wound dehiscence (3.0 per cent), and distal stenosis (1.5 per cent). 


\section{Conclusion}

The incidence of systemic complications was related to hemoglobin and serum protein/ albumin level and also to the age of patients and old age. Most common local complication was peristomal skin irritation which is caused by chemical dermatitis due to exposure to the stoma effluent because of leakage from appliance. Unavailability of suitable stoma appliance like Hollister due to cost factor causes, unavailability of stoma care nurse and illiteracy among patients increases morbidity. The stoma site must be in a location that is readily visible to the patient to allow for self-care. Like in obese patients, the stoma should be placed on the higher side of the belly to allow for visualization.

Meticulous skin care is mandatory with regular followup of these patients to provide opportunity to enquire and manage such problems. Enterostomal therapist, who is not posted at our centre, can provide direct patient care, education and counseling to patients with stoma. Stoma closure should always be done after a minimum period of 3 months as it is associated with lesser complications and allows time to gain weight and improve nutrition.

Funding: Nil, Conflict of interest: None initiated. Permission from IRB: Yes

\section{References}

1. Taylor P, An introduction to stomas: reasons for their formation, Nurs Times. 2005 Jul 19-25;101(29):63-4.

2. Geraldo Magela Salomé, Sergio Aguinaldo de Almeida, Maiko Moura Silveira, Quality of life and self-esteem of patients with intestinal stoma, Journal of Coloproctology Volume 34, Issue 4, OctoberDecember 2014, Pages 231-239.

3. Michael Kwiatt and Michitaka Kawata Avoidance and Management of Stomal Complications, Clin Colon Rectal Surg. 2013 Jun; 26(2): 112-121. doi: 10.1055/s0033-1348050.

4. Brian R. Kann, M.D. Stomas and Wound Management: Early Stomal Complications Clin Colon Rectal Surg. 2008 Feb; 21(1): 23-30. doi: 10.1055/s2008-1055318.

5. Marc I. Brand, Nadav Dujovny Preoperative Considerations and Creation of Normal Ostomies Clin Colon Rectal Surg. 2008 Feb; 21(1): 5-16. doi:
10. $1055 / \mathrm{s}-2008-1055316$.

6. Hellman J, Lago CP, Dermatologic complications in colostomy and ileostomy patients, Int J Dermatol. 1990 Mar;29(2):129-33.

7. Nastro P, Knowles CH, McGrath A, Heyman B, Porrett TR, Lunniss PJ, Complications of intestinal stomas, Br J Surg. 2010 Dec;97(12):1885-9. doi: 10. 1002/bjs.7259. Epub 2010 Sep 24.

8. Cheape JD, Hooks VH 3rd. Loop ileostomy: a reliable method of diversion, South Med J. 1994 Mar; 87(3):370-4.

9. Hwang YF, Chen SS, Liou TY, Wang HM, Hsu H, Complications of colostomies and colostomy closure, [Article in Chinese] Gaoxiong Yi Xue Ke Xue Za Zhi. 1990 Jun;6(6):276-82.

10. Akram Rajput, Abdul Samad, Tariq Wahab Khanzada Temporary Loop Ileostomy: Prospective Study of Indications and Complications RMJ. 2007; 32(2): 159-162.

11. Adnan Aziz, Irjan Sheikh Masood Jawant, Shamsudeen Alam, Manzar Saleem, Indications and complications of loop ileostomy, Journal of surgery Pakistan (international) 2009 Jul-Sept14(3).

12. Safirullah, Mumtaz N, Jan MA, Ahmed S. Complications of intestinal stomas. J Postgrad Med Inst. 2005;19(4):407-11.

13. Park JJ, Del Pino A, Orsay CP, Nelson RL, Pearl RK, Cintron JR, Abcarian H. Stoma complications: the Cook County Hospital experience. Dis Colon Rectum. 1999 Dec;42(12):1575-80.

14. Pearl RK, Prasad LM, Orsay CP, et al. Early local complications from intestinal stomas. Arch Surg 1985; 120: 1145-1147.

15. Duchesne JC, Wang Y, Weintraub SL, Boyle M, Hunt JP. Stoma complications: a multivariate analysis. Am Surg. 2002 Nov;68(11):961-6; discussion 966.

16. Robertson I, Leung E, Hughes D, et al. Prospective analysis of stoma-related complications. Colorectal Dis 2005; 7:279-285. 
17. Arumugam PJ, Bevan L, Macdonald L, et al. A prospective audit of stomas - analysis of risk factors and complications and their management. Colorectal Dis 2003; 5:49-52.

18. Jazair H. Saghir, Francis D. McKenzie, Deirdre M. Leckie, James S. McCourtney, Ian G. Finlay, Ruth F. McKee and John H. AndersonFactors that predict complications after construction of a stoma: a retrospective study. Eur J Surg 2001; 167:531-534.

19. Caricato M, Ausania F, Ripetti V, Bartolozzi F, Campoli G, Coppola R. Retrospective analysis of longterm defunctioning stoma complications after colorectal surgery. Colorectal Dis 2007; 9(6):559-561.

20. Kalashinikova I, Achkasov S, Fadeeva S, Vorobiev G. The development and use of algorithms for diagnosing and choosing treatment of ostomy complications: results of a prospective evaluation, Ostomy Wound Manage. 2011 Jan;57(1):20-7.

21. Formijne Jonkers HA, Draaisma WA, Roskott AM, van Overbeeke AJ, Broeders IA, Consten EC. Early complications after stoma formation: a prospective cohort study in 100 patients with 1-year follow-up, Int J Colorectal Dis. 2012 Aug; 27(8):10959. Epub 2012 Jan 31.

22. Redmond C, Cowin C, Parker T, The experience of faecal leakage among ileostomists.Br J Nurs. 2009 Sep24-Oct 7; 18 (17):S12-7.

23. Bass EM, Del Pino A, Tan A, Pearl RK, Orsay CP, Abcarian H. Does preoperative stoma marking and education by the enterostomal therapist affect outcome? Dis Colon Rectum 1997; 40:440-442.
24. Porter JA, Salvati EP, Rubin RJ, Eisenstat TE. Complication of colostomies. Dis Colon Rectum 1989; 32:299-303.

25. Bakx R, Busch OR, Bemelman WA, Veldink GJ, Slors JF, van Lanschot JJ. Morbidity of temporary loop ileostomies. Dig Surg. 2004; 21(4):277-81. Epub 2004 Aug 11.

26. van de Pavoordt HD, Fazio VW, Jagelman DG, Lavery IC, Weakley FL. The outcome of loop ileostomy closure in 293 cases, Int J Colorectal Dis. 1987 Nov;2(4):214-7.

27. Parks SE, Hastings PR. Complications of colostomy closure, Am J Surg. 1985 May; 149(5):672-5.

28. Pittman DM, Smith LE. Complications of colostomy closure, Dis Colon Rectum. 1985 Nov; 28 (11):836-43.

29. Khoury DA, Beck DE, Opelka FG, Hicks TC, Timmcke AE, Gathright JB Jr. Colostomy closure. Ochsner Clinic experience, Dis Colon Rectum. 1996 Jun; 39(6):605-9.

30. Mirelman D, Corman ML, Veidenheimer MC, Coller JA. Colostomies-indications and contraindications: Lahey Clinic experience, 1963-1974. Dis Colon Rectum. 1978 Apr; 21(3):172-6.

31. Bozzetti F, Nava M, Bufalino R, Menotti V, Marolda R, Doci R, Gennari L. Early local complications following colostomy closure in cancer patients, Dis Colon Rectum. 1983 Jan; 26(1):25-9.

\section{How to cite this article?}

Rajkumar, Singh M, Neogi P, Ajay SK, Gupta V. Profile of intestinal stomas at a tertiary referral centre of central India. Int J Med Res Rev 2016;4(6):881-888doi: 10.17511/ijmrr.2016.i06.04. 